\title{
CFD SIMULATION MODEL FOR MIXING TANK USING MULTIPLE REFERENCE FRAME (MRF) IMPELLER ROTATION
}

\author{
Ansar Ali, ThiyamTamphasana Devi \\ E-Mail Id: aliansar1994@gmail.com, thiyam85@gmail.com \\ Department of Civil Engineering, National Institute of Technology, Manipur
}

\begin{abstract}
In this work, CFD (Computational Fluid Dynamics) simulations have been conducted to investigate flow behavior of water in fully baffled stirred tank employed with Rushton impeller. The dimension of the inner rotating fluid zones in Multiple Reference Frame (MRF) impeller model plays an important role in accurately predicting the results on numerically based problems. Therefore, the aim of the paper is to develop CFD model, optimizing the dimensions of inner rotating fluid zone for MRF model (which is a numerical algorithm designed for modeling the rotating part i.e., impeller in stirred tank). Standard $\mathrm{k}-\varepsilon$ turbulence model which is a commonly used algorithm to model the turbulent fluid flow nature in the system is adopted. The velocity profile (radial and tangential velocity) are studied and compared with experimental results of Wu and Patterson (1989) and Rushton et al. (1950).Based on the comparison of correlation coefficient in the predictions of normalized mean velocities, zone 4 having diameter of $0.104 \mathrm{~m}$ and height of $0.032 \mathrm{~m}$ was found to be optimal for CFD modelling of stirred tank. The global flow parameters such as flow number predicted by CFD matched quite well with the data of Wu and Patterson (1989) and Rushton et al. (1950). The percentage deviation in the pumping number predictions at various radial locations show a percentage deviation less than $15 \%$ in comparison with experimental results.
\end{abstract}

Keywords: Computational Fluid Dynamics, Numerical Model, Rushton Impeller, Multiple Reference Frame Model. Notations

$\begin{array}{lll}\mathrm{a} & - & \text { impeller blade width }(\mathrm{m}) \\ \mathrm{b} & - & \text { impeller hub diameter }(\mathrm{m}) \\ \mathrm{C} & - & \text { off bottom impeller clearance }(\mathrm{m}) \\ \mathrm{C}_{\mu}, \mathrm{C}_{1 \varepsilon}, \mathrm{C}_{2 \varepsilon} & - & \text { constants of the } \mathrm{k}-\mathrm{e} \text { turbulence model } \\ \mathrm{d} & - & \text { impeller disc diameter }(\mathrm{m}) \\ \mathrm{D} & - & \text { impeller diameter }(\mathrm{m}) \\ \mathrm{h} & - & \text { impeller blade height }(\mathrm{m}) \\ \mathrm{H} & - & \text { height of fluid in the tank }(\mathrm{m}) \\ \mathrm{i}, \mathrm{j} & - & \text { coordinate directions } \\ \mathrm{k} & - & \text { turbulent kinetic energy }\left(\mathrm{m}^{2} / \mathrm{s}^{2}\right) \\ \mathrm{N} & - & \text { impeller speed }\left(\mathrm{s}^{-1}\right) \\ \mathrm{N}_{\mathrm{P}} & - & \text { impeller power number, } P /\left(\rho N^{3} D^{5}\right)(\text { dimensionless }) \\ \mathrm{N}_{\mathrm{Q}} & - & \text { Impeller flow number }\left(\mathrm{Q}_{\mathrm{r}} / \mathrm{ND}^{3}\right)(\text { dimensionless }) \\ \mathrm{N}_{\mathrm{Re}} & - & \text { impeller Reynolds number }\left(\rho N D^{2} / \mu\right)(\text { dimensionless }) \\ \mathrm{p} & - & \text { pressure }(\mathrm{Pa}) \\ \mathrm{P} & - & \text { power drawn by impeller }(\mathrm{W}) \\ \mathrm{Q}_{\mathrm{r}} & - & \text { pumping capacity }\left(\mathrm{m}^{3} / \mathrm{s}\right) \\ \mathrm{r} & - & \text { radial distance from impeller centre }(\mathrm{m}) \\ \mathrm{t} & - & \text { time }(\mathrm{s}) \\ \mathrm{T} & - & \text { tank diameter }(\mathrm{m}) \\ \mathrm{U}_{\text {tip }} & - & \text { impeller tip velocity }(\mathrm{m} / \mathrm{s}) \\ \mathrm{W} & - & \text { baffle width }(\mathrm{m}) \\ \mathrm{z} & - & \text { vertical distance from tank bottom }(\mathrm{m}) \\ & & \text { Greek symbols } \\ \varepsilon & - & \text { rate of dissipation of turbulence energy }\left(\mathrm{m}^{2} / \mathrm{s}^{3}\right) \\ \rho & - & \text { density }\left(\mathrm{kg} / \mathrm{m}^{3}\right) \\ \sigma_{\mathrm{k}}, \sigma_{\varepsilon} & - & \text { constants of the } \mathrm{k}-\mathrm{e} \text { turbulence model } \\ \theta & - & \text { tangential distance from impeller center } \mathrm{plane}(\mathrm{rad}) \\ \mu & - & \text { dynamic viscosity }(\mathrm{kg} / \mathrm{ms}) \\ \mu & & \end{array}$

\section{INTRODUCTION}

Mixing tanks are extensively used in the process industries such as chemical, pharmaceutical, food, oil and biochemical as well as in municipal and industrial wastewater treatment plants. Based on their applications, these are referred as mixing tanks, stirred tanks, agitated tanks and aeration tanks. The choice of tank geometry and type of impeller varies widely depending upon the purpose of application carried out in the mixer such as blending of miscible liquids, solid suspension, dispersion of gas into liquid, heat and mass transfer enhancement etc. [1]. In 
order to get good product quality with optimum economical way, it is important to know the degree of mixing, performance and behavior inside the tanks. Thus, it is important to investigate mixing hydrodynamics inside the stirred tank [2]. The large amount of energy is required for a mixing process which causes major expenses. The cost of poor mixing from a multinational chemical company was estimated at $\$ 100$ million per year in 1993 [3]. Day by day the cost of energy is increasing, so it is essential to do the optimum design analysis of mixing tanks. On account of extensive use of stirred vessels in process industries, major price saving is possible with minor reduction in operational costs. Even though continuous efforts have been done to enhance the performance of different impellers with consideration of their pumping capacity and level of mixing attained, a variety of impellers being evolved and lead into virtual applications [4]. The flow structure inside the stirred tank has been investigated with sophisticated flow measurement techniques such as laser Doppler anemometry (LDA), particle image velocimetry (PIV) and laser sheet illumination (LSI). Even though these experimental studies have measured flow field accurately, these techniques were neither economical nor practical because the best choice for geometry of tank and impeller type varies depending on the purpose of operation carried out in stirred tank [2].In baffled systems the rotating impellers generate high turbulence and complex flow structure as the flow induced by them interacts with baffles mounted on wall of tank. It is very difficult to understand flow structure due to complexity in flow generated. With the consideration of the issues mentioned above, in recent years computational fluid dynamics (CFD) tool has been extensively used to understand such complex behavior inside stirred tanks. In the literature, various approaches have been adopted to investigate the flow pattern generated in stirred tank. In the past, flow simulations have been done with 'black box' approach, in that impeller region was excluded from computational domain in stirred tank [5]. Even though this technique gives the successful prediction of flow field, this technique requires the experimental data including turbulence quantities while this data is available only for few vessel geometries [5], [6] \& [7]. Different techniques have been proposed for the modeling of stirred tank with rotating impellers to overcome the flaws pointed in the 'black box' method. In the sliding mesh approach, the stirred vessel is segmented in two sections, the first one impeller containing section and second section contains the volume of liquid, vessel wall, vessel base and the baffles. The grid generated in the impeller occupied section moves with impeller; however, the grid in vessel section remains in stationary condition. Sliding mesh technique is more beneficial as it does not require any boundary conditions acquired from experiments. On the account of computational expenses, sliding mesh approach is more costly for the start up problems and this approach is not economical for design purpose [4]. The second optimistic approach, multiple reference frame (MRF), was put for modeling of impeller rotation [8]. In this approach, stirred vessel is partitioned into two frames, i.e. a moving frame and stationary frame. MRF approach was used for modeling of baffled stirred tank with propeller rotor; the results obtained for time averaged computational mean velocities were found to be in good agreement with LDA measurements [9]. The third approach is the snapshot flow model [7]. This model was suitable to predict the flow around the impeller and did not require the experimental data. The snap shot model as well as MRF model are steady state models but the later model is widely adopted by various researches in comparison with former model [5], [6]. Snapshot model does not consider impeller baffle interactions which considerably affect the accuracy of flow field predictions in baffled stirred tanks. But MRF method properly accounts the impeller baffle interactions by dividing into rotating zone containing impeller and stationary zone containing baffles. Further snap shot model is not widely validated throughout the entire flow domain in any stirred tank as compared to MRF model [11]. Thus, MRF technique is computationally less expensive and does not require any experimental data [4] \& [12]. Accurate prediction of fluid turbulence is major challenge in the CFD modeling for stirred tank. Three different ways have been documented in the literature: (1) Reynolds averaged Navier-Stokes (RANS) equations, (2) direct numerical simulation (DNS) and (3) large eddy simulations (LES). In RANS approach, the instantaneous flow variables are decomposed into the mean and fluctuating components. This is the most widely used approach for engineering problems [12] as it is computationally more economical compared to DNS and LES. In order to solve the RANS equations, it requires appropriate turbulence model. Different turbulence models have been applied to study the flow in stirred tanks [13] \& [14]. The instantaneous flow variables are solved and no modeling is required in the case of DNS. However, all scales from smallest to largest are resolved in case of RANS model. In LES, smallest scales are modeled and large scales are resolved. Literature suggests, RANS turbulence model and MRF impeller rotation model are suitable for modelling of stirred tank. Due to high speed of impeller rotation, the flow variations are very sharp near the impeller. The effective region for sharp variation in flow is 1.5 times of blade height above and below the impeller disc and D/2 away from the impeller tip [15]. Following this concept, same dimensions have been adopted for inner rotating fluid zone in MRF technique in the CFD modeling of stirred tank by [10].

As concerned with the use of MRF technique for impeller rotation model, no proper method is available in the literature for how the dimensions of inner rotating zones are considered in this study. With this consideration of the issue for the selection of inner rotating fluid zone, this work has been done to find the optimal dimension of inner rotating fluid zone considering different diameter and height of inner rotating fluid zone. Also, only few works have been done to develop the CFD model to characterize the hydrodynamics inside the stirred or mixing tank which will be ultimately useful for optimal design of tanks. The optimal inner rotating fluid zone is considered where simulation results for velocity predictions such as tangential velocity, radial velocity and axial velocity were found to be in reasonable agreement with experimental results [16] Also, the efficiency of optimal MRF zone is 
ICACCG2020 30-31 July, 2020, Ansal University, Gurgaon, India International Journal of Technical Research \& Science (Special Issue)

investigated by comparing the power number predictions at various Reynolds numbers with the classical experimental results [17].

\section{TANK CONFIGURATION AND IMPELLER GEOMETRY}

The system investigated in this study consists of a $15 \mathrm{~cm}$ diameter cylindrical tank with four equally spaced baffles and agitated by a standard six-bladed Rushton turbine impeller (Fig. 2.1\&Table- 2.1). This system was chosen as it is more or less a research standard configuration for stirred tanks and is sufficiently small to investigate very fine grids. Water at $25^{\circ} \mathrm{C}$ (density $=997 \mathrm{~kg} / \mathrm{m} 3$, dynamic viscosity $=0.00089 \mathrm{~kg} / \mathrm{ms}$ ) was used as the test fluid. In this study, results are compared with the experimental data of $\mathrm{Wu}$ and Patterson (1989). The speed of impeller (N) was kept at $850 \mathrm{rpm}$ for finding the optimal dimensions of inner rotating zone.

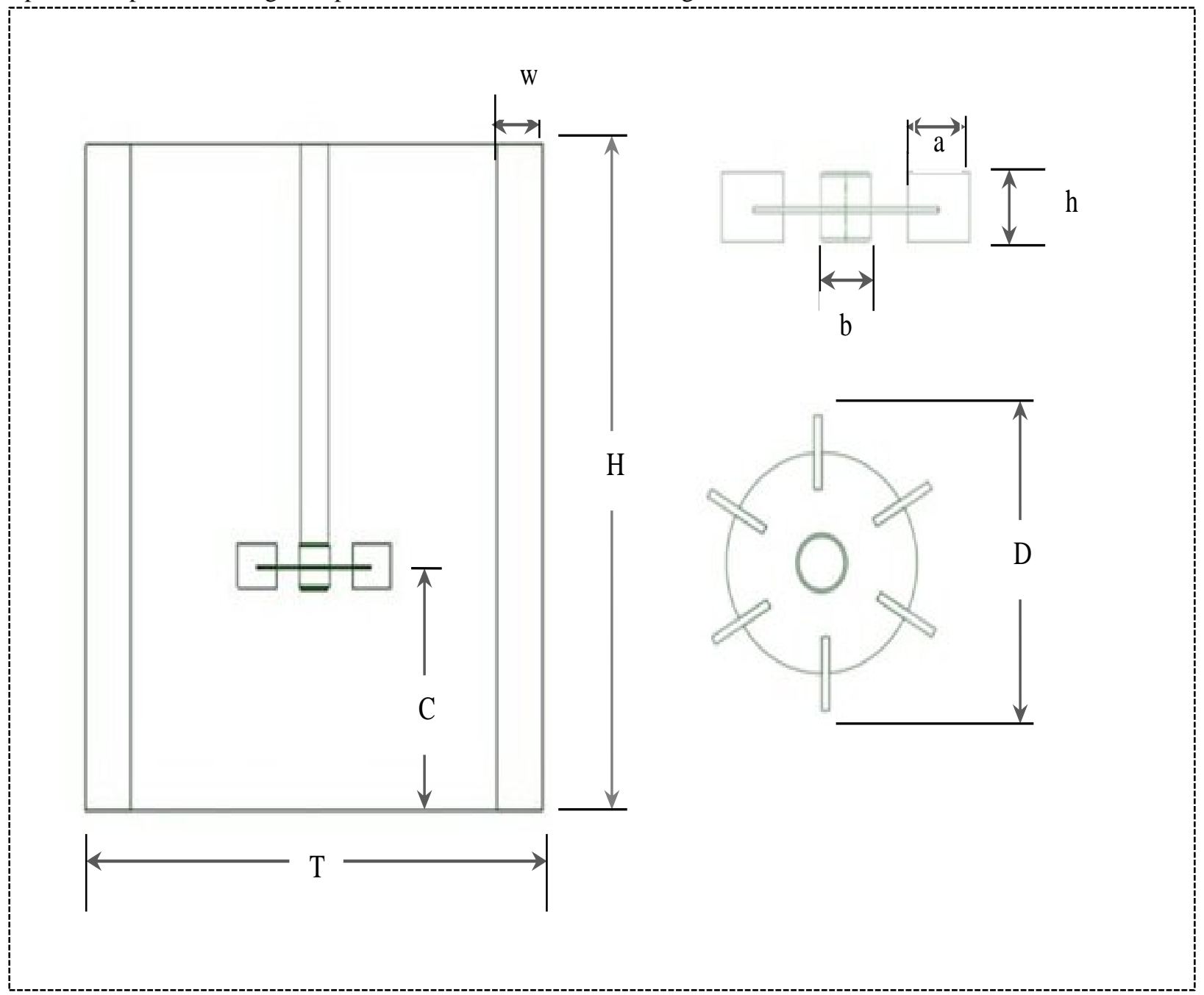

Fig. 2.1 Dimensions of Rushton Impeller Stirred Tank

Table-2.1 Dimensions of The Vessel and Impeller

\begin{tabular}{|l|c|c|c|c|c|c|c|c|}
\hline Dimension & $\mathrm{H} / \mathrm{T}$ & $\mathrm{C} / \mathrm{T}$ & $\mathrm{D} / \mathrm{T}$ & $\mathrm{w} / \mathrm{T}$ & $\mathrm{d} / \mathrm{D}$ & $\mathrm{a} / \mathrm{D}$ & $\mathrm{h} / \mathrm{D} / \mathrm{D}$ & \\
\hline Length, size & 1 & $1 / 3$ & $1 / 3$ & $1 / 10$ & $3 / 4$ & $1 / 4$ & $1 / 5$ & $1 / 5$ \\
\hline
\end{tabular}

\section{COMPUTATIONAL METHODOLOGY}

Finite volume method is used to solve the governing flow equations. ANSYS Fluent $18.1{ }^{\circledR}$ software package is used for modeling of stirred tank. The flow domain is divided into small volumes and mesh is created using meshing tool available in ANSYS. An unstructured tetrahedral mesh is produced for fluid region while for rotor and baffles structured hexahedral mesh [18] has been used as shown in Fig. 3.2. Since the stirred tank and expected flow show rotational symmetry, only half of the tank geometry was used as the calculation domain (i.e. $180^{\circ}$ geometry, 2 baffles, 3 impeller blades) by applying cyclic boundary conditions [10]. The boundary conditions adopted for CFD model of stirred tank is shown in Fig. 3.1. Momentum and turbulence quantities are discretized by second-order scheme. Pressure staggering option scheme is adopted for pressure. The velocity and pressure are coupled through 
ICACCG2020 30-31 July, 2020, Ansal University, Gurgaon, India International Journal of Technical Research \& Science (Special Issue)

the semi-implicit method for pressure linked equations algorithm [19]. To attain better convergence and stability in the solution, the under relaxation factor was kept at lower value.

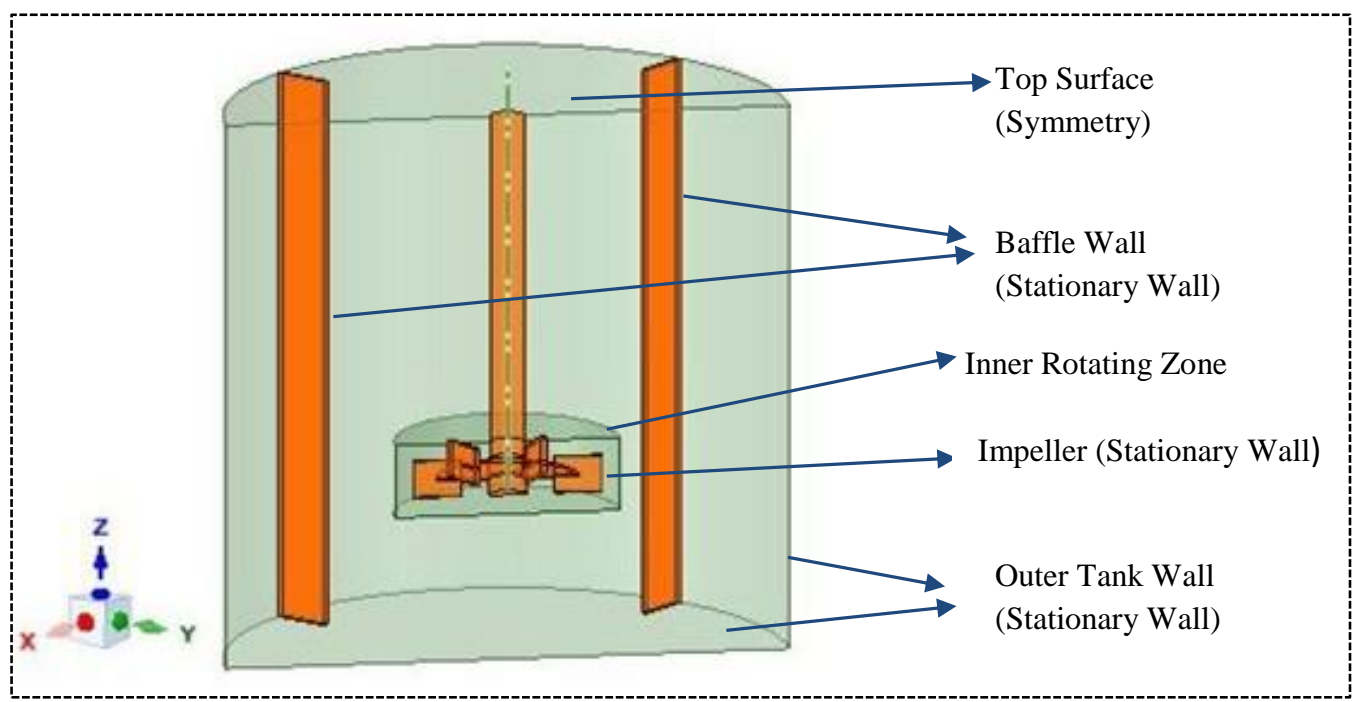

Fig.3.1 Boundary Conditions Adopted for CFD Model

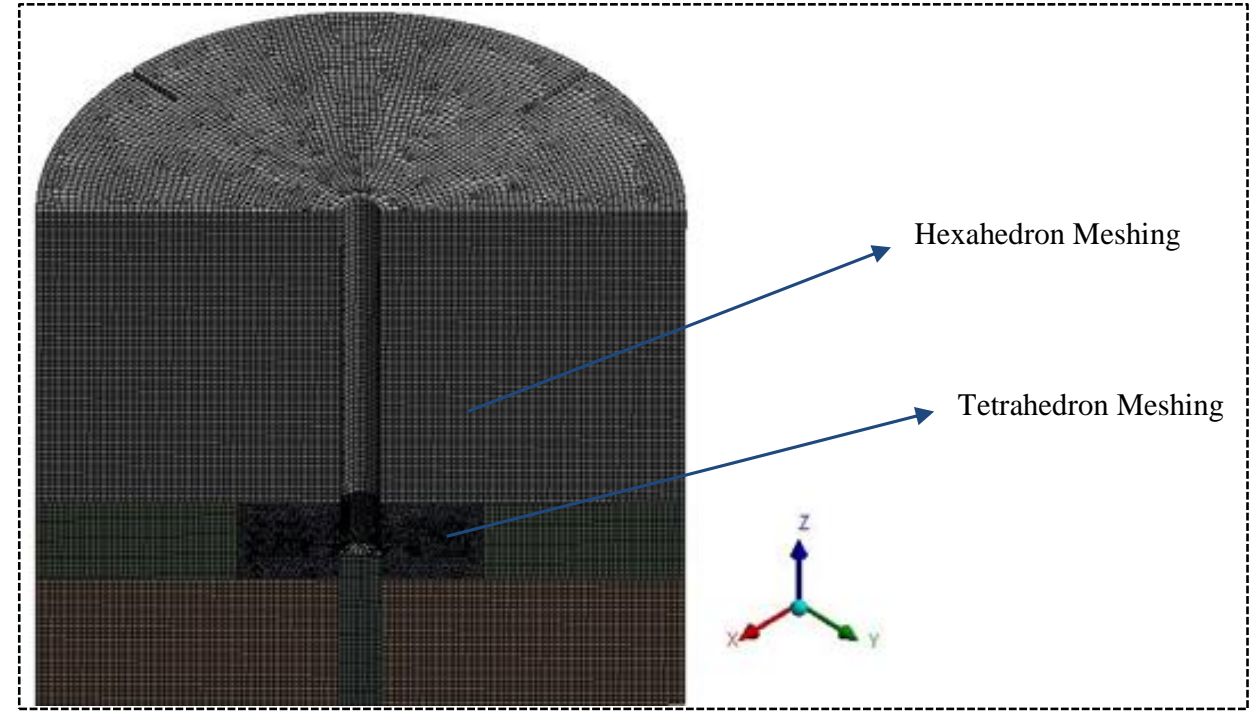

Fig. 3.2 Meshing For Different Parts of CFD Model of the Stirred Tank

\section{MODEL EQUATIONS AND TURBULENCE MODELS}

\subsection{Model Equations}

Flow behavior inside stirred tank is solved by discretized governing equations. The governing equations are the Navier-Stokesequations, which solve the mass and momentum conservation equations and provide solution for flow variables such as velocity and pressure. Applying the mass, momentum and energy conservation, we can derive the continuity equation in Equation 4.1 and momentum equation in Equation 4.2, 4.3 \& 4.4 respectively.

The continuity or mass conservation equation is given by

$$
\frac{\partial \mathrm{u}}{\partial \mathrm{x}}+\frac{\partial \mathrm{v}}{\partial \mathrm{y}}+\frac{\partial \mathrm{w}}{\partial \mathrm{z}}=0
$$

The momentum conservation equations for incompressible flow are given by

$$
\begin{aligned}
& \rho \frac{\mathrm{Du}}{\mathrm{Dt}}=\rho \mathrm{g}_{\mathrm{x}}-\frac{\partial \mathrm{p}}{\partial \mathrm{x}}+\mu\left(\frac{\partial^{2} \mathrm{u}}{\partial \mathrm{x}^{2}}+\frac{\partial^{2} \mathrm{u}}{\partial \mathrm{y}^{2}}+\frac{\partial^{2} \mathrm{u}}{\partial \mathrm{z}^{2}}\right) \\
& \rho \frac{\mathrm{Dv}}{\mathrm{Dt}}=\rho \mathrm{g}_{\mathrm{y}}-\frac{\partial \mathrm{p}}{\partial \mathrm{y}}+\mu\left(\frac{\partial^{2} \mathrm{v}}{\partial \mathrm{x}^{2}}+\frac{\partial^{2} \mathrm{v}}{\partial \mathrm{y}^{2}}+\frac{\partial^{2} \mathrm{v}}{\partial \mathrm{z}^{2}}\right)
\end{aligned}
$$


ICACCG2020 30-31 July, 2020, Ansal University, Gurgaon, India

International Journal of Technical Research \& Science (Special Issue)

$$
\rho \frac{\mathrm{Dw}}{\mathrm{Dt}}=\rho \mathrm{g}_{\mathrm{z}}-\frac{\partial \mathrm{p}}{\partial \mathrm{z}}+\mu\left(\frac{\partial^{2} \mathrm{w}}{\partial \mathrm{x}^{2}}+\frac{\partial^{2} \mathrm{w}}{\partial \mathrm{y}^{2}}+\frac{\partial^{2} \mathrm{w}}{\partial \mathrm{z}^{2}}\right)
$$

Where $\mathrm{u}, \mathrm{v}$ and $\mathrm{w}$ are the fluid velocities in the $\mathrm{x}, \mathrm{y}$ and $\mathrm{z}$ directions, respectively, and $\mathrm{p}$ is the local pressure.

\subsection{Turbulence Models}

The URANS model used is the standard k-epsilon model implemented in Fluent. For the turbulent Reynolds number range ( $\left.\mathrm{N}_{\mathrm{Re}} \geq 7000\right)$, the standard $\mathrm{k}$-e turbulence model and model constants were used (given in Table 4.1).

\begin{tabular}{|c|c|c|c|c|}
\hline \multicolumn{5}{|c|}{ Table-4.1 Standard k-e Model Constants } \\
\hline $\mathrm{C}_{\mu}$ & $\sigma_{\mathrm{k}}$ & $\sigma_{\varepsilon}$ & $\mathrm{C}_{1 \varepsilon}$ & $\mathrm{C}_{2 \varepsilon}$ \\
\hline 0.09 & 1.0 & 1.3 & 1.44 & 1.92 \\
\hline
\end{tabular}

\section{RESULTS AND DISCUSSION}

\subsection{Fluid Zones in MRF}

In this study, the validity of CFD model is tested by comparing the hydrodynamic parameters with experimental data inside the stirred tanks. In this study, qualitative and quantitative comparison of CFD results with experimental literature ( $\mathrm{Wu}$ and Patterson) has been done in terms of velocity fields and global flow parameters inside the tank. The dimensions of inner rotating zones are increased from zone 1 to zone 5 as shown in Table5.1. Zone 1 is very close to impeller tip and zone 5 is near to baffles shown in Fig. 5.1.

Table-5. Fluid Zone Numbers and Corresponding Dimensions.

\begin{tabular}{|l|c|c|}
\hline $\begin{array}{l}\text { Inner Rotating Fluid } \\
\text { Zone Number }\end{array}$ & Height (m) & Diameter (m) \\
\hline 1 & 0.020 & 0.052 \\
\hline 2 & 0.023 & 0.057 \\
\hline 3 & 0.030 & 0.094 \\
\hline 4 & 0.032 & 0.104 \\
\hline 5 & 0.034 & 0.114 \\
\hline
\end{tabular}

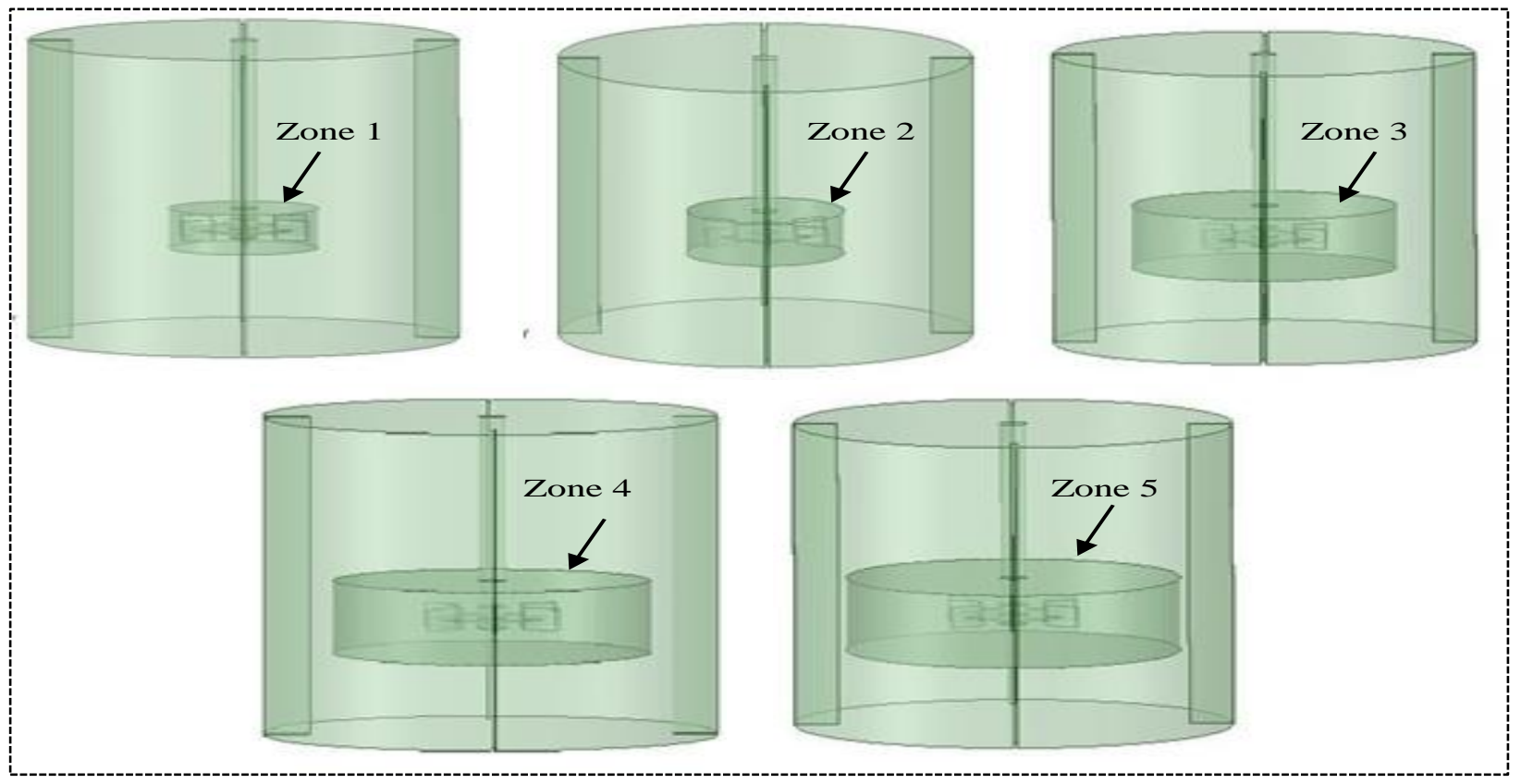

Fig.5.1 Diagrammatic Representation of Inner Rotating Fluid Zones

\subsubsection{Prediction of Mean Velocities}

In this section, CFD results are predicted in terms of mean radial, tangential and axial velocities normalized with the impeller tip speed. In the literature, experimental studies of Wu and Patterson (1989) have been widely used for the comparison of velocity fields. The measurement has been done at radial distance of $2.75 \mathrm{~cm}$ and at an angle of $45^{\circ}$. 
ICACCG2020 30-31 July, 2020, Ansal University, Gurgaon, India International Journal of Technical Research \& Science (Special Issue)

ISSN No.:2454-2024 (online)

The comparison between CFD predictions and literature data of mean velocity fields at different inner rotating zone is depicted in Fig.5.2 and Fig.5.3.

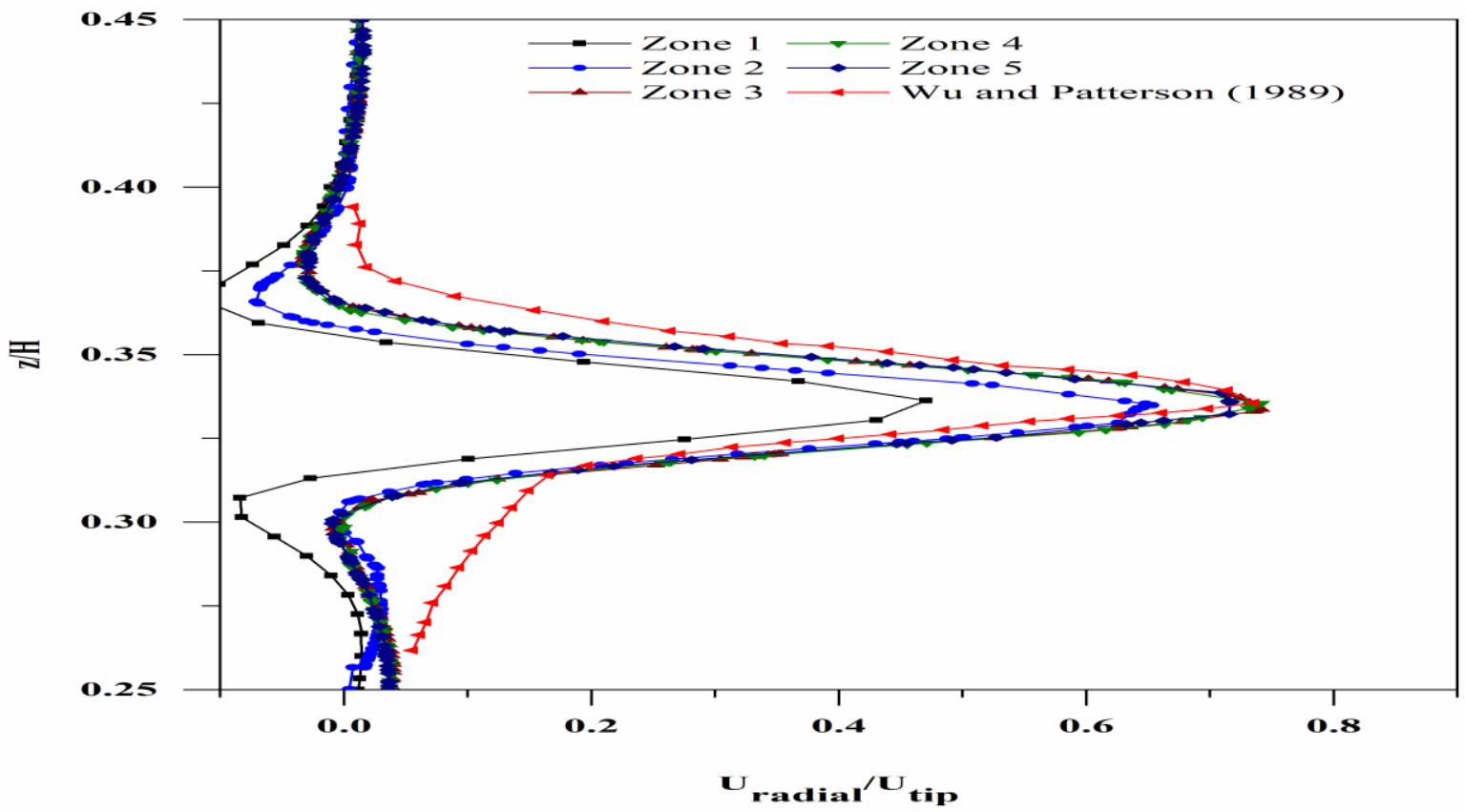

Fig. 5.2 Comparison of Mean Radial Velocity Profiles between Wu and Patterson (1989) and CFD Predictions for Different Inner Rotating Fluid Zones

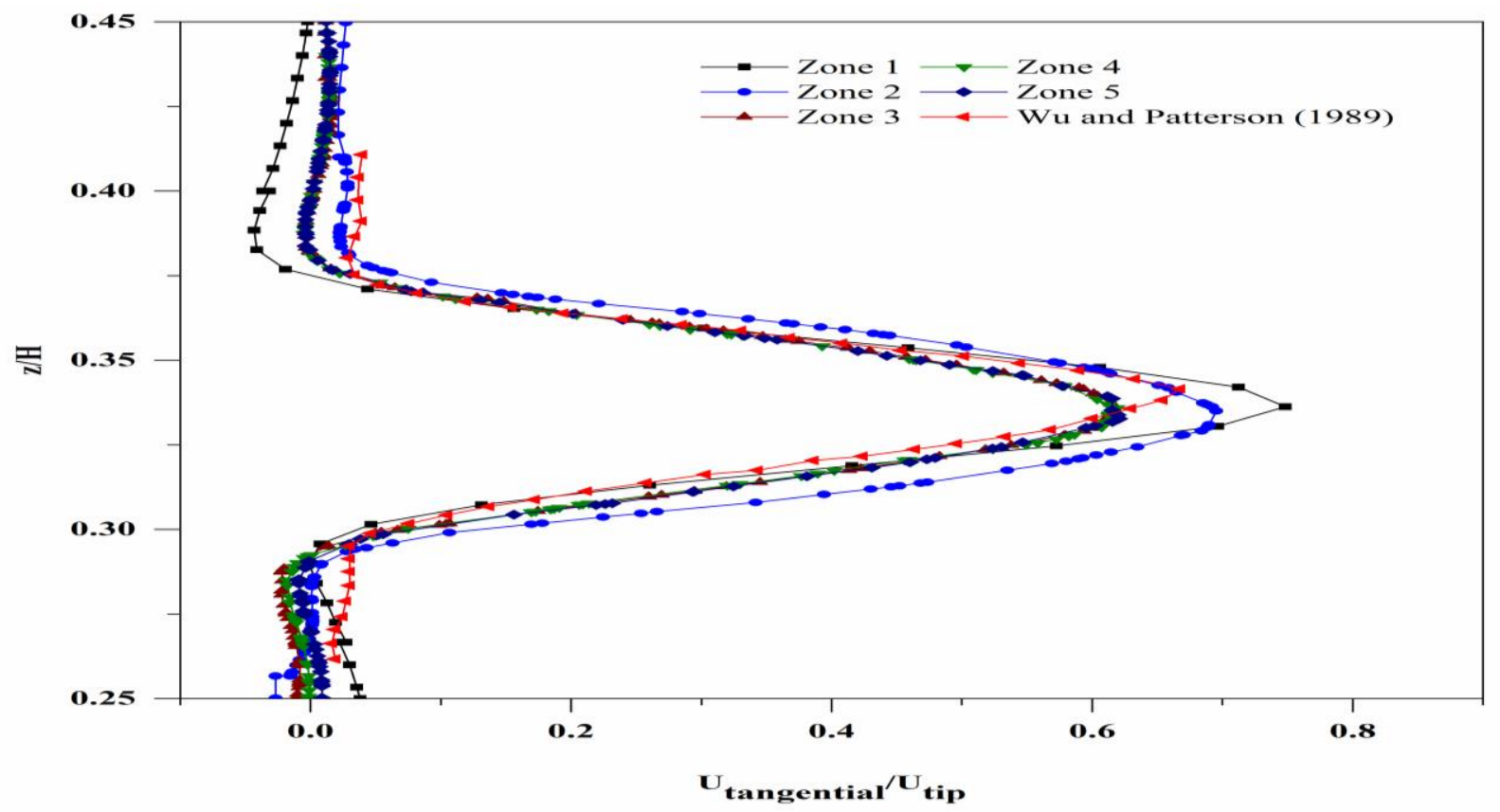

Fig.5.3 Comparison of Mean Tangential Velocity Profiles between Wu and Patterson (1989) and CFD Predictions for Different Inner Rotating Fluid Zones

At plane $\mathrm{z}=5 \mathrm{~cm}$, the value of radial and tangential velocities reached to maximum, as there is sharp variation in flow fields due to continuous rotation of impeller. The peak value of mean radial velocity predicted by CFD at zone 4 is in good agreement with literature data compared to other zones (Fig.5.2). Mean tangential velocities are well predicted by CFD as shown in Fig.5.3.The axial location of peak tangential velocity is shifted below as compared with experiments. The trend of tangential velocity observed at zone 4 is in good agreement with literature data compared to other zones (Fig.5.3).

In order to find the best inner rotating fluid zone among all five different inner rotating fluid zones under consideration, the CFD results of mean radial and mean tangential are quantitatively measured in terms of correlation coefficient [20]. The best value of correlation coefficient for radial and tangential velocity is found at zone 4 as shown in Fig.5.4. 

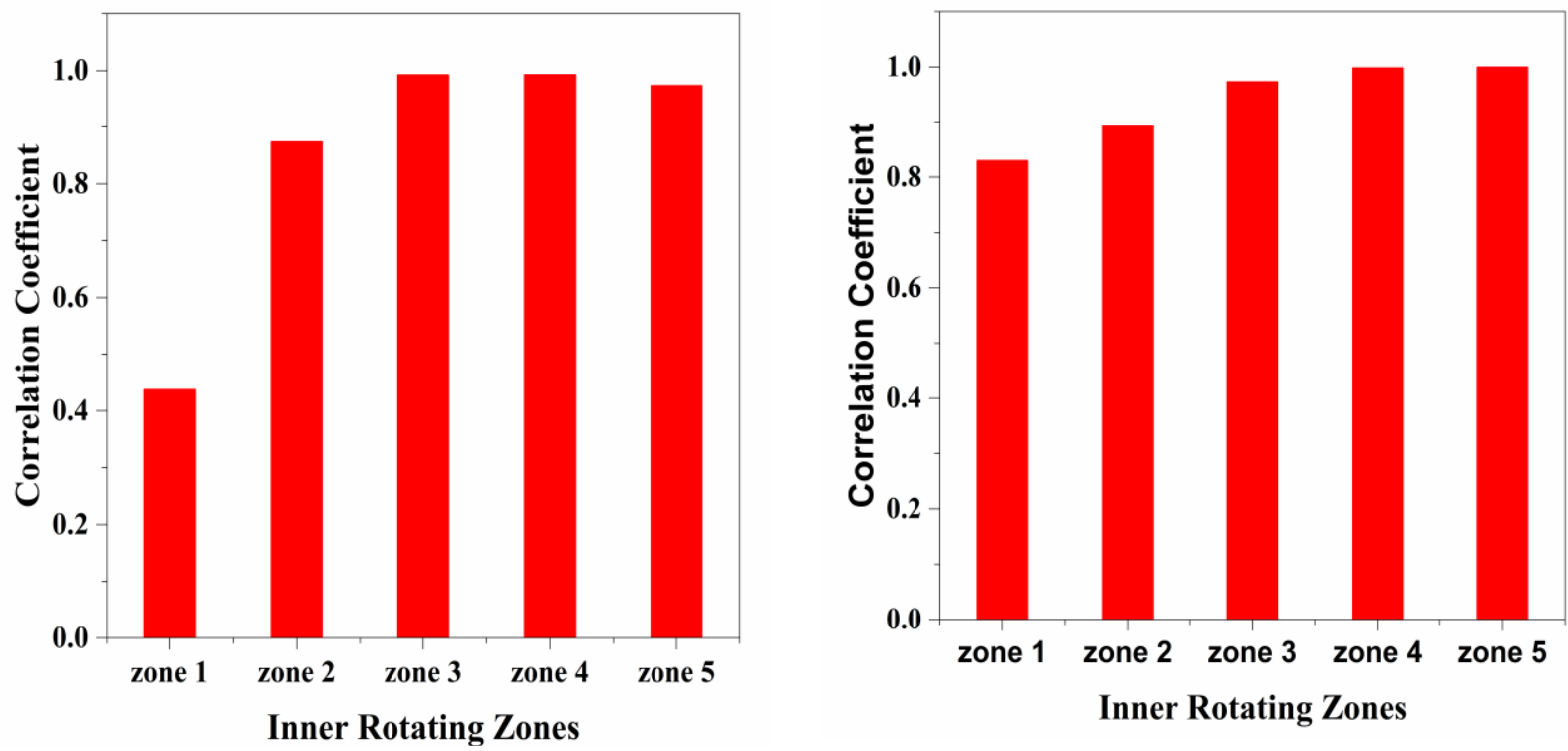

Fig. 5.4 Correlation Coefficient for Mean Radial and Tangential Velocity for Different Zone

From Fig.5.4 the correlation coefficient for radial velocity increases from zone 1 to zone 4 and decreases at zone 5 . Correlation coefficient in radial velocity for different zones in comparison with literature data is found at zone 4 . As the Rushton turbine is the radial flow impeller, the flow variations predominantly happen due to radial and tangential velocities. The CFD results at zone 4 are found to qualitatively and quantitatively best match with literature data and hence the dimensions considered at zone 4 is optimal dimensions for CFD modelling of stirred tank. Further, the zone 4 is considered to investigate the radial pumping capacity.

\subsection{Impeller Pumping Capacities}

Flow number is one of the global flow characteristic which is generally defined in experimental and computational works to validate their results. The flow number defines rate of liquid circulation in mixing tanks. The flow number is calculated by normalizing radial pumping capacity with $\mathrm{ND}^{3}$. Here, in Equation 5.1, radial pumping capacities are obtained by integrating the mean radial velocities over the axial positions $\mathrm{z}_{1}=0.035$ toz $=0.065$. The speed of impeller was kept at $200 \mathrm{rpm}$. The trend of flow number versus radial position is shown in Fig.5.5. The radial pumping capacity increases with increase in radial distance from the impeller tip due to the fluid entrainment.

$$
\mathrm{Q}_{\mathrm{r}}=2 \pi \mathrm{r} \int_{\mathrm{z}_{1}}^{\mathrm{z}_{2}} \mathrm{U}_{\mathrm{r}} \mathrm{d}_{\mathrm{z}}
$$

The percentage deviation in pumping number values at most of the radial locations is less than $15 \%$. This shows a good match of CFD results with that of experimental results of Wu and Patterson (1989). But the pumping number near the wall shows large variations from the experimental results and this may be due to the limitations of RANS approach as well as k- $\varepsilon$ turbulence model in predicting turbulence parameters as suggested by Deglon and Meyer 2006. They also argue that the thickness of blade and impeller disc is not revealed in literature of Wu and Patterson (1989) which can significantly affect the pumping number. The results of Rushton et al. (1950) show slight deviations from the CFD results as well as results of Wu and Patterson (1989) due to the variations in impeller geometry, operating conditions and measurement techniques (Wu and Patterson 1989).

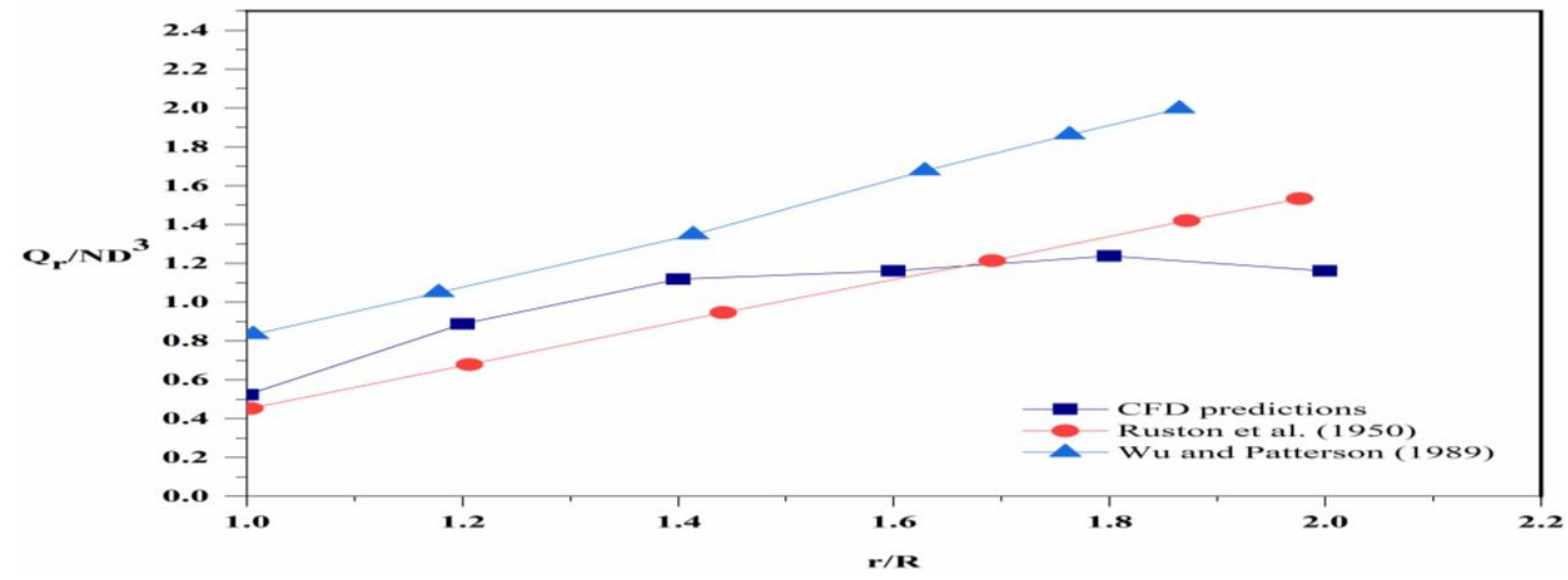

Fig. 5.5 Flow Number at Different Radial Positions

DOI Number: https://doi.org/10.30780/specialissue-ICACCG2020/026 


\section{CONCLUSIONS}

The CFD model for stirred tank with Rushton has been developed and steady-state simulations have been conducted. Based on the comparison of correlation coefficient in the predictions of normalized mean velocities, zone 4 having diameter of $0.104 \mathrm{~m}$ and height of $0.032 \mathrm{~m}$ was found to be optimal for CFD modelling of stirred tank. With the optimized zone, predictions of flow parameters from CFD model show good match with experimental results. The percentage deviation in the pumping number predictions at various radial locations show a percentage deviation less than $15 \%$ in comparison with experimental results.

\section{REFERENCES}

[1] Stasiek, J., Ciofalo, M.W., Chew, P.E, "Investigation of flow and heat transfer in corrugated passages-I. Experimental results”. International Journal of Heat and Mass Transfer, Vol.39, PP 149-164, 1996.

[2] Yapici, K., Karasozen, B., Schafer, M., Uludag, Y., "Numerical investigation of the effect of the Rushton type turbine design factors on agitated tank flow characteristics". Chemical Engineering and Processing: Process Intensification, Vol.47, pp 1340-1349, 2008.

[3] Paul, EL., Atiemo-Obeng, VA., Kresta, SM, "Handbook of industrial mixing: Science and practice WileyInterscience". 2004.

[4] Dewan, A., Nassar, AF., \& Durst, F., "Fluid dynamics and mixing of single-phase flow in a stirred vessel with a grid disc impeller: Experimental and numerical investigations" Chemical Engineering Science, Vol.61, pp 2815-2822, 2006.

[5] Brucato, Ciofalo, Grisafi \& Micale, "Numerical prediction of flow fields in baffled stirred vessels: A comparison of alternative modelling approaches". Chemical Engineering Science, Vol.53, pp3653-3684, 1998.

[6] Ranade, VV., "Computational fluid dynamics for reactor engineering”. Chemical Engineering, Vol.11, pp2191-0235, 1995.

[7] Ranade, VV. \& Dommeti, SMS, “Computational Snapshot of Flow Generated by Axial Impeller in Baffled Stirred Vessels". Chemical Engineering Research \& Design, Vol.74, pp476-484, 1996.

[8] Luo, JY.,Issa, RL., Gosman, AD, "Prediction of impeller induced flows in mixing vessels using multiple frames of reference". 8th European Conf. on Mixing, Cambridge, Vol.13, No.6, pp549-556, 1994.

[9] Naude, Xuereb, Bertrand, "Direct prediction of the flows induced by a propeller in an agitated vessel using an unstructured mesh". The Canadian Journal of Chemical Engineering, Vol.76, pp631-640, 1998.

[10] Deglon, DA., Meyer, CJ, “CFD modelling of stirred tanks: Numerical considerations”. Minerals Engineering, Vol.19, pp1059-1068, 2006.

[11] Joshi, Nere, Rane, Murthy, Mathpati, Patwardhan, Ranade, "CFD simulation of stirred tanks: Comparison of turbulence models (Part II: Axial flow impellers, multiple impellers and multiphase dispersions)". The Canadian Journal of Chemical Engineering, Vol.89, pp754-816, 2011.

[12] Khopkar, Mavros, Ranade, Bertrand, "Simulation of flow generated by an axial-flow impeller. Batch and Continuous Operation”. Chemical Engineering Research and Design, Vol.82(A6), pp737-751, 2004.

[13] Murthy, B. N., \& Joshi, J. B., "Assessment of standard k-RSM and LES turbulence models in a baffled stirred vessel agitated by various impeller designs”. Chemical Engineering Science, Vol.63, pp5468-5495, 2008.

[14] Gimbun, J., Rielly, CD., Nagy, ZK \& Derksen, KK, "Detached eddy simulation on the turbulent flow in a stirred tank”. American Institute of Chemical Engineers, Vol.58, pp3224-3241, 2012.

[15] Lee, K.C., \& Yianneskis, M., "The extent of periodicity of the flow in vessels stirred by Rushton impellers". AIChE Symposium Series, Vol.90, pp5-18, 1994.

[16] Wu, H., and Patterson, GK, "Laser-Doppler measurements of turbulent flow parameters in a stirred mixer". Chemical Engineering Science, Vol.44, pp2207-2221, 1989.

[17] Rushton, JH., Costich, EW., Everett, HJ., "Power characteristics of mixing impellers-Part II". Chemical Engineering Progress, Vol.46, pp467-476, 1950.

[18] Patil,H., Patel, AK., Pant, J., Vinod, AV, “CFD simulation model for mixing tank using multiple reference frame (MRF) impeller rotation”. ISH Journal of Hydraulic Engineering, pp2164-3040, 2018.

[19] ANSYS Inc. (2013). ANSYS Fluent 14.5 Theory Guide, Canonsburg, Pennsylvania.

[20] Barnston, A.G., "Correspondence among the correlation, RMSE, and Heidke forecast verification measures; refinement of Heidke score”. Wea. Forcasting, Vol.7, No.4, 699-709, 1992. 